Research Article

\title{
Relationship between Corrosion of Reinforcement and Surface Cracking Width in Concrete
}

\author{
Jian Cao $\mathbb{D}^{1},{ }^{1}$ Liangfang Liu, ${ }^{1}$ and Shangchuan Zhao $^{2}$ \\ ${ }^{1}$ School of Civil and Architectural Engineering, Nanchang Institute of Technology, Nanchang 330099, China \\ ${ }^{2}$ Ministry of Transport Research Institute of Highways, Beijing 100088, China \\ Correspondence should be addressed to Jian Cao; caojian1980@126.com
}

Received 12 August 2019; Revised 21 November 2019; Accepted 4 January 2020; Published 22 January 2020

Academic Editor: Mohamed ElGawady

Copyright $(2020$ Jian Cao et al. This is an open access article distributed under the Creative Commons Attribution License, which permits unrestricted use, distribution, and reproduction in any medium, provided the original work is properly cited.

\begin{abstract}
The durability of structure cannot be guaranteed when a corrosion expansion crack reaches the surface of the reinforced concrete member. In this paper, firstly, based on the existing theoretical model of steel corrosion degree, the calculation process of the model and the determination of the relevant parameters in the model were analyzed and discussed. Secondly, the stiffness reduction factor of concrete in the model was calculated according to the existing experimental data, and the engineering formula of the steel corrosion degree was established, which was related to the surface crack width of reinforced concrete. Moreover, the experiments of steel bar corrosion were carried out with different components of surface crack width, in which the parameters of the bar diameter, concrete protection layer thickness, and water-cement ratio were taken into consideration. The experimental phenomena and results were further analyzed and discussed. Finally, comparing with the experimental data, the engineering formula presented in the paper was validated. The results show that the calculated values by the engineering formula are in better agreement with the experimental values than those by the existing model, which provide a theoretical basis for further study on the durability limit state of the structure.
\end{abstract}

\section{Introduction}

Steel bar in a reinforced concrete structure located in coastal areas are bounded to different degrees of corrosion due to chloride ions, resulting in cracking and peeling of the concrete cover, which is badly endangering the reliability of the structure. Although there are different views on how to define the structural durability limit state, it is affirmed that the cracking of the concrete cover induced by the steel corrosion is one of the durability limit states of the reinforced concrete structure [1].

According to the serviceability limit states of structure, there is a limit for the presence of surface crack width of the concrete component. However, it is possible that the structure of security or durability has been destroyed before the limit is reached. Present studies mainly focus on the two stages of the off time of steel bar and the crack initiation time of the concrete protective layer, and the calculation equations of the time of the steel bar corrosion and crack expansion have also been deduced [2-4]. However, the investigation on the corrosion rate of steel after corrosion cracking is still insufficient. However, in the tests, the researchers found that the corrosion degree has a significant effect on the component surface crack width, and it is in relevance with the parameters including the concrete strength grade, component size, thickness of concrete protection layer, and diameter of the steel [5-8]. There is a lack of contrast and regularity among the results due to different methods and conditions of the tests. In the aspect of numerical simulation, the finite element models established by $\mathrm{Du}$ et al. [9] and Chen and Leung [10] simulated the corrosion process of the component surface, and the evolution law of the corrosion expansion stress was calculated by the numerical analysis method. However, in the process of finite element modeling, certain assumptions on the properties and constitutive relation of materials were required to put forward, on which the test data were insufficient for comparison, so the results of numerical 
calculation were not validated. In the aspect of the theoretical model, Cao et al. [11] discussed the interaction between the crack propagation and the corrosion medium propagation and presented a theoretical model of the corrosion rate of the steel bar during the coupling process of micro- and macrochloride corrosion. Based on the size effect and reliability theory, taking into account the actual size of the structure and physical environment, Papakonstantinou and Shinozuka [12] proposed the calculation model of the corrosion rate of reinforcing steel bar in the large size structure. According to Bossio et al. [13, 14], three- and fourlayer models for concrete cracking were proposed, as well as a model to correlate surface cracks with internal corrosion depending on many parameters (distance of cracks on external surface, concrete cover, bar dimeter, and accounting for different reliabilities of these data at inspection time). Paul et al. [15-18] investigated on accelerated chloride-induced corrosion in cracked reinforced strain-hardening cement-based composites and reinforced mortar beams, both in loaded and unloaded states. Li et al. [19-22] carried out a series of theoretical and experimental studies on the relationship between the surface crack width and rust expansion rate, combining with concrete material mechanics and elastic mechanics theory. They provided an analytical model for corrosion-induced crack width in the concrete structure when taking the softening characteristics of concrete after cracking into consideration. Moreover, Lau et al. [23] proposed a new methodology for predicting the time to corrosion-induced concrete cracking based on fracture mechanics criteria. Nevertheless, there are still disadvantages because of the complex propagation behaviors of corrosive cracks in the concrete and insufficient knowledge on the corrosive mechanism of concrete, which presents the complex calculation process in the existing model and significant discreteness of the computing results, as well as the difficulties to determine the parameters in the model. Recently, the effects of nonuniform rebar corrosion are concerned and accurate performance evaluation can be achieved by experimental studies [24-27].

As one of the basic parameters that can reflect the applicability of the structure, the width of the corrosion expansion crack can be easily obtained in the detection of the actual structure. Thus, on the premise that the structure safety is not destroyed, which has a great significance to adopt nondestructive detection on surface crack width of measurement units for tracking the corrosive crack propagation behavior and grasping the dynamic rules of reinforcement corrosion in concrete. In this paper, firstly, based on the existing studies, the calculation process and related parameters of the existing model [19] were analyzed and discussed. Secondly, in order to simplify the calculation of the model [19], the existing test data were utilized for the regression calculation of stiffness degradation factor in the model [19], and the engineering formula of steel corrosion degree was presented in the paper. Moreover, considering the parameters including the bar diameter, concrete cover thickness, and water-cement ratio, tests concerning the relationship between the steel corrosion degrees and crack width were conducted, and the phenomena and results of the tests were analyzed and discussed. Finally, the engineering formula presented in the paper was compared and validated by the test data, and suggestions on its applicability were proposed.

\section{Materials and Methods}

2.1. Li-CQ's Model. Based on the material mechanics and elasticity theory of concrete, Li et al. $[19,20]$ analyzed the expansion cracking region of the damaged protective layer of concrete resulted from steel corrosion, considering concrete with embedded steel bars to be a thick wall cylinder, as shown in Figures 1(a)-1(c).

In Figure 1(a), $D$ is the diameter of reinforcement bar; $C$ is the thickness of the concrete cover; the inner and outer radii of the thick wall cylinder are $a=\left(D+2 d_{0}\right) / 2$ and $b=C+\left(D+2 d_{0}\right) / 2 ; r$ means the distance from any point in the thick walled cylinder of the concrete protection layer to the center of the steel bar, which is the function of the radial coordinate; $d_{0}$ is the thickness of the annular layer of concrete pores (that is, a pore band) at the interface between the bar and concrete; and $d_{0}$ is usually constant once concrete has hardened.

In Figure 1(b), $P_{1}(t)$ is the applied load at time $t$ via the transverse (radial) component of the bond stress between the bar and concrete caused by the products of corrosion of the reinforcing steel bar and $d_{s}(t)$ is the thickness of a ring of the corrosion product formed as the corrosion propagates in concrete at time $t$, which can be obtained by the following equation:

$$
d_{s}(t)=\frac{W_{\text {rust }}(t)}{\pi\left(D+2 d_{0}\right)}\left(\frac{1}{\rho_{\text {rust }}}-\frac{\alpha_{\text {rust }}}{\rho_{\text {st }}}\right),
$$

where $\alpha_{\text {rust }}$ is a coefficient related to the type of corrosion products, $\rho_{\text {rust }}$ is the density of corrosion products, $\rho_{\text {st }}$ is the density of steel, and $W_{\text {rust }}(t)$ is the mass of corrosion products at time $t$. Then, the degree of steel corrosion can be expressed by

$$
\theta=\frac{W_{\text {rust }}(t)}{W} \times 100 \%
$$

where $W$ is the initial mass of steel bar and $\theta$ is the degree of steel corrosion (\%).

According to Bažant and Planas [28], the stiffness reduction factor $\alpha$ is dependent on the average tangential strain $\overline{\varepsilon_{\theta}}$ throughout $\left[a, r_{0}\right]$, which is represented as follows:

$$
\alpha=\frac{f_{t} \exp \left[-\gamma\left(\overline{\varepsilon_{\theta}}-\overline{\varepsilon_{\theta}^{c}}\right)\right]}{E_{\mathrm{ef}} \overline{\varepsilon_{\theta}}}
$$

where $f_{t}$ is the tensile strength of concrete, $\overline{\varepsilon_{\theta}^{c}}$ denotes the average tangential cracking strain, and $\gamma$ is a material constant, which can be defined between 5000 and 10000 . According to [29], the approximate value of $\gamma$ is 7500 . 


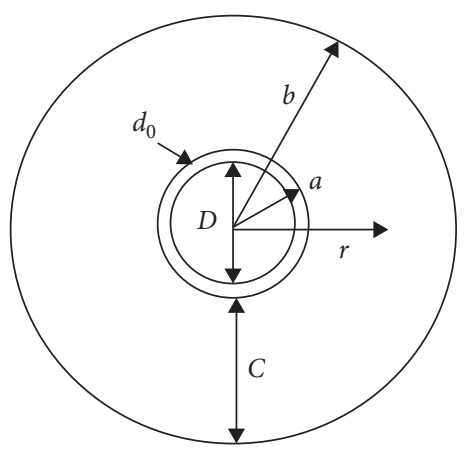

(a)

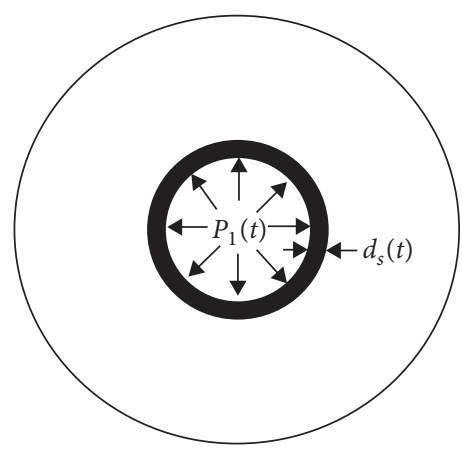

(b)

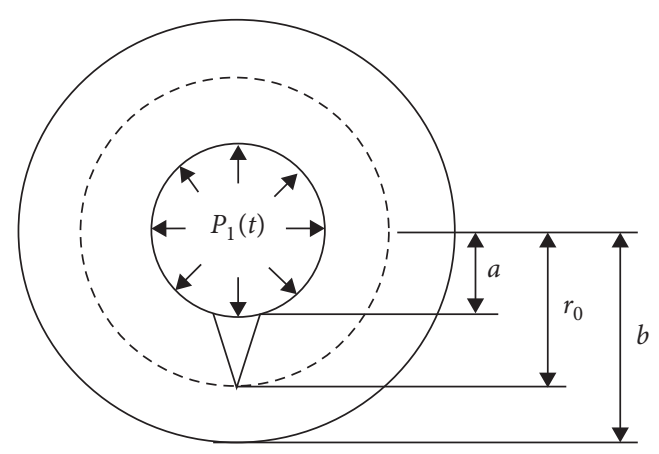

(c)

FiguRE 1: Schematic of crack evolution: (a) reinforced concrete considered to be a thick wall cylinder; (b) expansion stress caused by corrosion products; (c) concrete cover cracking.

After initiation, the compressive stress of the thick wall cylinder of the concrete protection layer is increasing with the continuous growth of corrosion products. The crack divides the thick wall cylinder into two coaxial cylinders: inner cracked and outer uncracked ones, as shown in Figure 1(c). According to the elastic theory of concrete, as the result of the corrosion crack in concrete protective layer arising, the governing equation for the displacement $u(r)$ of any point $r$ in the concrete protective layer should satisfy the following equation [19]:

$$
\frac{\mathrm{d}^{2} u(r)}{\mathrm{d} r^{2}}+\frac{1}{r} \cdot \frac{\mathrm{d} u(r)}{\mathrm{d} r}-\alpha \frac{u(r)}{r^{2}}=0,
$$

in which $u$ is the displacement of the point $O$ along the $s$-axis, as shown in Figure 2.

The solution to equation (4) can be expressed as

$$
u(r)=c_{1}\left(r_{0}\right) r^{\sqrt{\alpha}}+c_{2}\left(r_{0}\right) r^{-\sqrt{\alpha}} .
$$

At present, the boundary conditions of equation (5) require that

$$
\begin{aligned}
c_{1}\left(1+v_{c}\right) b^{(\sqrt{\alpha}-1)}-c_{2}\left(1-v_{c}\right) b^{(-\sqrt{\alpha}-1)} & =0, \\
c_{1} a^{\sqrt{\alpha}}+c_{2} a^{-\sqrt{\alpha}} & =d_{s}(t),
\end{aligned}
$$

where $v_{c}$ is Poisson's ratio of concrete in equation (6). $c_{1}$ and $c_{2}$ can be obtained by solving equations (6) and (7) simultaneously as follows:

$$
\begin{aligned}
& c_{1}=\frac{\left(1-v_{c}\right) a^{\sqrt{\alpha}}}{\left(1-v_{c}\right) a^{2 \sqrt{\alpha}}+\left(1-v_{c}\right) b^{2 \sqrt{\alpha}}} d_{s}(t), \\
& c_{2}=\frac{\left(1-v_{c}\right) a^{\sqrt{\alpha}} b^{2 \sqrt{\alpha}}}{\left(1-v_{c}\right) a^{2 \sqrt{\alpha}}+\left(1-v_{c}\right) b^{2 \sqrt{\alpha}}} d_{s}(t) .
\end{aligned}
$$

According to $\mathrm{Li}$ et al. [19], the corresponding average tangential strain $\overline{\varepsilon_{\theta}}$ can be indicated as follows:

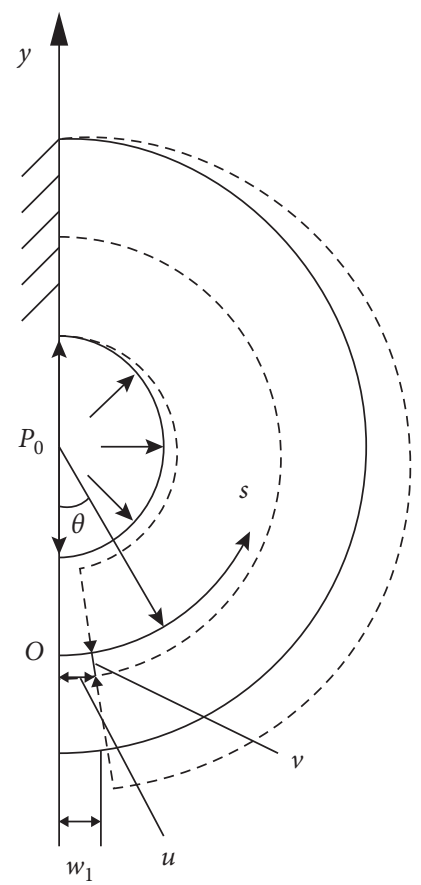

FIgURE 2: Model for calculation of initial crack width.

$$
\begin{aligned}
\overline{\varepsilon_{\theta}} & =\frac{1}{b-a} \int_{a}^{b} \varepsilon_{\theta}(r) \mathrm{d} r=\frac{1}{b-a} \int_{a}^{b}\left(c_{1} r^{(\sqrt{\alpha}-1)}+c_{2} r^{(-\sqrt{\alpha}-1)}\right) \mathrm{d} r \\
& =\frac{\left(b^{\sqrt{\alpha}}-a^{\sqrt{\alpha}}\right)\left[c_{1}+\left(c_{2} /(a b) \sqrt{\alpha}\right)\right]}{\sqrt{\alpha}(b-a)} .
\end{aligned}
$$

The average tangential strain over the cracked surface $\overline{\varepsilon_{\theta}^{c}}$ can be determined as follows:

$$
\overline{\varepsilon_{\theta}^{c}}=\frac{1}{b-a} \int_{a}^{b}\left(c_{1}(r)+\frac{c_{2}(r)}{r^{2}}\right) \mathrm{d} r .
$$

Consequently, the stiffness reduction factor $\alpha$ can be indicated as 


$$
\alpha=\frac{f_{t} \exp \left\{-\gamma\left[\left(\left(b^{\sqrt{\alpha}}-a^{\sqrt{\alpha}}\right)\left[\left(c_{1}+c_{2}\right) /(a b)^{\sqrt{\alpha}}\right]\right) /(\sqrt{\alpha}(b-a))-(1 /(b-a)) \int_{a}^{b}\left(c_{1}(r)+\left(c_{2}(r) / r^{2}\right)\right) \mathrm{d} r\right]\right\}}{\left(E_{\mathrm{ef}}\left(b^{\sqrt{\alpha}}-a^{\sqrt{\alpha}}\right)\left[\left(c_{1}+c_{2}\right) /(a b)^{\sqrt{\alpha}}\right]\right) /(\sqrt{\alpha}(b-a))} .
$$

Afterward, by substituting equations (8) and (9) into equation (12), the relationship between $\alpha$ and $d_{s}(t)$ can be calculated.

With $c_{1}$ and $c_{2}$ known, the tangential strain at $b$ can be determined from equation (5), that is,

$$
\varepsilon_{\theta}(b)=c_{1} b^{(\sqrt{\alpha}-1)}+c_{2} b^{(-\sqrt{\alpha}-1)} .
$$

In Figure 2, evidently, in accordance with the geometric relationship between the width and the angle of the crack on the surface of the concrete component, the crack width $w_{c}$ on the surface of the concrete cylinder should be

$$
w_{c}=2 \pi b\left[\varepsilon_{\theta}(b)-\varepsilon_{\theta}^{e, m}(b)\right],
$$

where $\varepsilon_{\theta}^{e, m}(b)$ is the maximum elastic strain at $r=b$ and equal to the following equation [30]:

$$
\varepsilon_{\theta}^{e, m}(b)=\frac{\sigma_{\theta, m}(b)-v_{c} \sigma_{r}(b)}{E_{\mathrm{ef}}},
$$

where $\sigma_{\theta, m}(b)$ and $\sigma_{r}(b)$ are the maximum tangential stress and radial stress at $r=b$, respectively, and $E_{\text {ef }}$ is the effective elastic modulus of concrete, in which $E_{\mathrm{ef}}=E_{c} /\left(1+\varphi_{\mathrm{cr}}\right)$ and $\varphi_{\text {cr }}$ is the coefficient of concrete creep.

On account of $\sigma_{r}(b)=0$ and $\sigma_{\theta, m}(b)=f_{t}$, the crack width $w_{c}$ is finally given by

$$
\begin{aligned}
w_{c} & =2 \pi b\left[c_{1} b^{(\sqrt{\alpha}-1)}+c_{2} b^{(-\sqrt{\alpha}-1)}-\frac{f_{t}}{E_{\mathrm{ef}}}\right] \\
& =\frac{4 \pi d_{s}(t)}{\left(1-v_{c}\right)(a / b)^{\sqrt{\alpha}}+\left(1+v_{c}\right)(b / a)^{\sqrt{\alpha}}}-\frac{2 \pi b f_{t}}{E_{\mathrm{ef}}},
\end{aligned}
$$

where the essential variables are the thickness of corrosion products $d_{s}(t)$ and the stiffness reduction factor $\alpha . d_{s}(t)$ is directly related to the corrosion degree, as shown in equation (1), and $\alpha$ is related to concrete geometry and property. Obviously, with the accumulation of corrosion products, the crack width increases with time. This makes sense both theoretically and practically, as experienced and observed $[6-8,31]$.

In $[32,33]$, the values of basic variables in equations (1) and (16) had been provided, where $d_{0}=12.5 \mu \mathrm{m}, \alpha_{\text {rust }}=0.57$, $\rho_{\text {rust }}=3600 \mathrm{~kg} / \mathrm{m}^{3}$, and $\rho_{\text {st }}=7850 \mathrm{~kg} / \mathrm{m}^{3}$. Parameters $a, b, D$, $C, f_{t}, E_{c}, v_{c}$, and $\varphi_{\text {cr }}$ can be determined by the size of the component and the performance of concrete materials.

Therefore, the calculation process of Li-CQ's model includes the following steps:
(1) Determine the basic parameters of reinforced concrete members, and the relationship between the steel corrosion product thickness $d_{s}(t)$ and concrete stiffness reduction factor $\alpha$ can be calculated in association with equations (8), (9), and (12).

(2) Substitute the relationship with $d_{s}(t)$ and $\alpha$ to equation (16), and the relationship between the crack width $w_{c}$ and $d_{s}(t)$ can be obtained.

(3) Substitute $d_{s}(t)$ represented by $w_{c}$ to equation (1), and the relationship between $w_{c}$ and $W_{\text {rust }}(t)$ can be established. Furthermore, the model of the corrosion degree of steel bar can be calculated by equation (2).

2.2. Engineering Formula considering the Reduction Coeffcient of Stiffness. In Li-CQ's model, the calculation process of parameters $d_{s}(t)$ and $\alpha$ is an iterative process, which is more complicated and inconvenient. In addition, when the difference method is used to calculate equation (12), the accuracy of calculation results could not be guaranteed if the difference step is large, while the computation burden will be doubled if the difference step is small. Therefore, parameters in the Li-CQ's model should be simplified for engineering applications.

In equation (16), parameters $D, C, f_{t}$, and $E_{c}$ can be determined by the size of the current concrete members and concrete material properties. The value of Poisson's ratio $v_{c}$ is 0.18 in common. Concrete creep coefficient $\varphi_{\text {cr }}$ can be obtained by CEB-FIP Model Code 2010 [33].

For concrete stiffness reduction factor $\alpha$, considering the influence of the corrosion time of steel bar, the data in the literature $[20-22,34-38]$ were applied to calculate the simplified calculation of $\alpha^{\prime}(t)$, and the nonlinear regression equation can be indicated as follows:

$$
\begin{aligned}
\alpha^{\prime}(t)= & 0.01137638 \times\left(\frac{t}{365}\right)^{(-2.198836253)} \\
& +0.1235655576\left(\operatorname{adj} . R^{2}=0.974\right),
\end{aligned}
$$

where $\alpha^{\prime}(t)$ denotes modified concrete stiffness reduction factor and $t$ is the time of steel corrosion, day as the unit.

Consequently, substituting equations (16) and (17) into equation (1), the modified parameter of the mass of corrosion products $W_{\text {rust }}^{\alpha}(t)$ can be proposed as follows:

$$
W_{\text {rust }}^{\alpha}(t)=\frac{\left(w_{c}+\left(2 \pi b f_{t} / E_{\text {ef }}\right)\right) \cdot\left(D+2 d_{0}\right) \cdot\left[\left(1-v_{c}\right)(a / b)^{\sqrt{\alpha^{\prime}(t)}}+\left(1+v_{c}\right)(b / a)^{\sqrt{\alpha^{\prime}(t)}}\right]}{4 \cdot\left(\left(1 / \rho_{\text {rust }}\right)-\left(\alpha_{\text {rust }} / \rho_{\text {st }}\right)\right)} .
$$


Thus, the modified calculation of the steel corrosion degree can be expressed as

$$
\theta^{\alpha}=\frac{W_{\text {rust }}^{\alpha}}{W} \times 100 \% .
$$

2.3. Experimental Programs. Experiments were designed to investigate the influence on the relationship between corrosion degree of steel bar and corrosion-induced crack width by parameters including water-cement ratio, the thickness of concrete cover, and diameter of steel bar, and the engineering formula presented above was verified through the experiment.

2.3.1. Mix Design. In the experiments, materials including ordinary Portland cement (with $60.6 \mathrm{MPa}$ of the 28-day standard compressive strength), continuous grading gravel with diameters from 5 to $25 \mathrm{~mm}$, medium sand with diameters from 0.08 to $2.0 \mathrm{~mm}$, as well as a kind of naphthalene-based superplasticizer were used to produce concrete. The yield strength of steel bar is $335 \mathrm{MPa}$. Experiments [39] indicate that a certain amount of chloride mixed with concrete can significantly reduce the resistivity of the concrete and distinguish steep corrosion speed because of different mixed concretes. Under this circumstance, not only the steel corrosion degree is accelerated but also an appropriate corrosion current density is applied. The mix proportion is listed in Table 1.

2.3.2. Specimen Design. To achieve the experimental objective, the size of the specimen is $300 \mathrm{~mm} \times 200 \mathrm{~mm} \times 250 \mathrm{~mm}$, as shown in Figure 3 .

In Figure 3, C1, C2, and C3 represent the thickness of concrete cover of the diameter steel bar of $12 \mathrm{~mm}, 20 \mathrm{~mm}$, and $25 \mathrm{~mm}$, respectively. The thickness of the concrete cover is $30 \mathrm{~mm}, 40 \mathrm{~mm}$, and $50 \mathrm{~mm}$, respectively. The predetermined corrosive cracks width on the member surface is set to $0.2 \mathrm{~mm}, 0.4 \mathrm{~mm}, 0.7 \mathrm{~mm}$, and $1.1 \mathrm{~mm}$. The orthogonal design method [40] of L9 (34) was adopted in the tests. The levels of test parameters are shown in Table 2, in which each number includes two specimens.

In addition, the same batches of concrete specimens were indwelled to determine the basic $28 \mathrm{~d}$ mechanical properties of concrete materials: 6 groups of elasticity modulus specimens, 3 groups of cube compressive strength specimens, and 3 groups of splitting tensile strength specimens.

2.3.3. Specimen Preparation. Firstly, the steel bars of different diameters were cut to $300 \mathrm{~mm}$ in length, the steel rust on the steel surface was cleaned, and the initial weight of steel was recorded. The molds were manufactured according to Figure 3, and the steel bars were fixed in the reserved holes of the molds. Next, fresh concrete was poured into the molds and was vibrated compaction. The molds were removed after 24 hours; both ends of the steel bars were cleaned up and then welded with wires and sealed by epoxy resins. Finally, the test specimens and referenced specimens were put into
TABLE 1: Mix proportion of concrete $\left(\mathrm{kg} / \mathrm{m}^{3}\right)$.

\begin{tabular}{lcc}
\hline No. & W/C & $\begin{array}{c}\text { Water }: \text { cement }: \text { sand }: \text { macadam }: \\
\text { water-reducing agent }: \text { sodium chloride }\end{array}$ \\
\hline S1 & 0.3 & $126: 378: 586: 1244: 8.4: 4.2$ \\
S2 & 0.4 & $168: 378: 549: 1168: 8.4: 4.2$ \\
S3 & 0.5 & $210: 378: 514: 1092: 8.4: 4.2$ \\
\hline
\end{tabular}

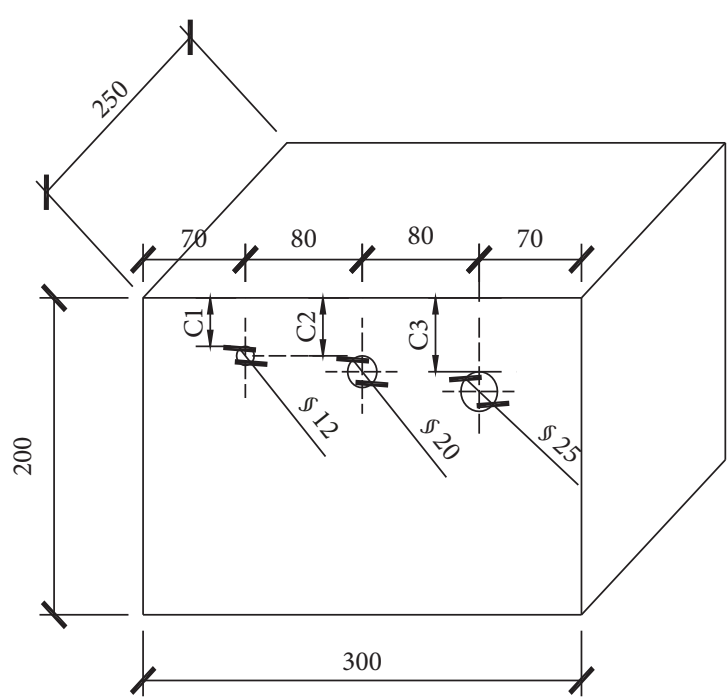

Figure 3: Size of the specimen (unit: $\mathrm{mm}$ ).

the curing room together and conducted for testing after 28 days of standard curing. The formed reinforced concrete specimens are shown in Figure 4.

2.3.4. Testing Procedure. In the accelerated steel corrosion test, the specimens were soaked in $5 \% \mathrm{NaCl}$ solution and the steel bars were connected with each other in parallel via wires reinforced by the voltage of $60 \mathrm{~V}$ until the cracking on the specimen surface was developing into the preset width. After breaking the specimens in batches, corroded steels were soaked in hydrochloric acid solution next and then were washed clean after the surface acidic substance was neutralized by calcium carbonate solution. Finally, the corrosive steel reinforcements were weighted by the electronic balance accurate to $0.1 \mathrm{~g}$, and the corrosion degrees of the steel bars were calculated. Experimental procedures are shown in Figures 5 and 6.

2.3.5. Phenomena and Analysis of Experiment. In the experiment, it can be observed that (1) with the progress of energization and steel corrosion, it appeared heating was done within the specimen and the surface temperature was rising. The reason can be explained that concrete generates more heat, while current gets through the concrete in the condition of continuous power as it is a poor conductor with large resistance. (2) A small amount of bubbles and damp phenomenon could be observed at the concrete near the cathodic protection, and there were drops of water generated at reinforced ends. After energization for some days, there 
TABLE 2: The levels of test parameters.

\begin{tabular}{|c|c|c|c|c|}
\hline $\begin{array}{l}\text { Parameter level } \\
\text { no. }\end{array}$ & $\mathrm{W} / \mathrm{C}$ & $\begin{array}{l}\text { Thickness of concrete protection layer } \\
(\mathrm{mm})\end{array}$ & $\begin{array}{l}\text { Diameter of steel bar } \\
(\mathrm{mm})\end{array}$ & $\begin{array}{l}\text { Preset crack width in the surface of concrete } \\
\qquad(\mathrm{mm})\end{array}$ \\
\hline 1 & 0.3 & 30 & 12 & $0.2 / 0.4 / 0.7 / 1.0$ \\
\hline 2 & 0.3 & 40 & 20 & \\
\hline 3 & 0.3 & 50 & 25 & \\
\hline 4 & 0.4 & 30 & 25 & $0.2 / 0.4 / 0.7 / 1.0$ \\
\hline 5 & 0.4 & 40 & 12 & \\
\hline 6 & 0.4 & 50 & 20 & \\
\hline 7 & 0.5 & 30 & 20 & $0.2 / 0.4 / 0.7 / 1.0$ \\
\hline 8 & 0.5 & 40 & 25 & \\
\hline 9 & 0.5 & 50 & 12 & \\
\hline
\end{tabular}

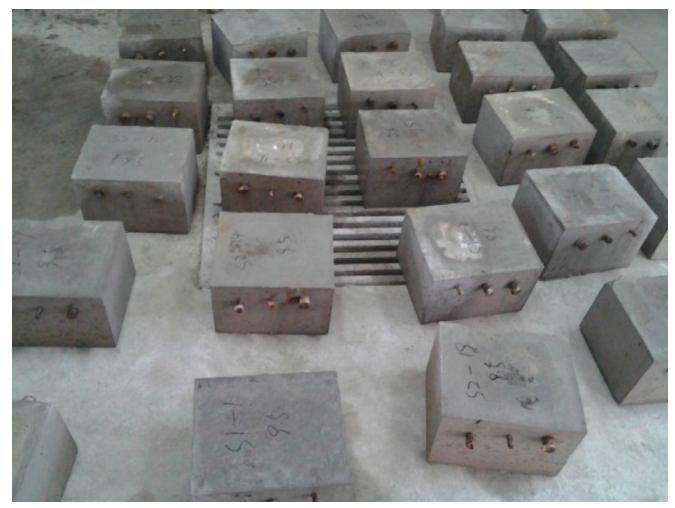

FIGURE 4: The formed reinforced concrete specimens.

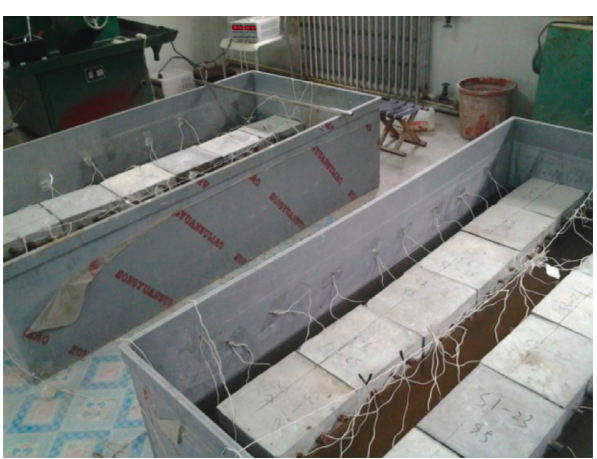

FIGURE 5: Energized accelerate steel corrosion test.

were cracks on the surface on the reinforced concrete specimen, and overflow rust obviously appeared in the position of cracks and the end of steel bars, which was caused by the concrete pores around the steel bars which was filled with the corrosion products generated due to continuous steel corrosion. (3) The larger the concrete water-cement ratio was, the earlier the crack appeared, and the greater the corrosion degree of steel was when cracks appeared. The thickness of concrete cover also had certain influence on the development patterns of crack. (4) After breaking the specimens, the longitudinal ribs of steels were usually the origin of the crack. This is because the stress concentration was arising at the longitudinal ribs of steel, resulting in large expansion force applied on concrete surrounding. (5) The

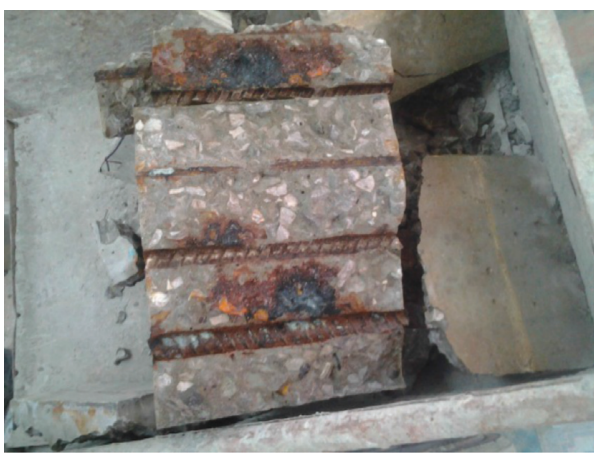

FIGURE 6: Specimen breakages.

longitudinal cracks, with uniform width, were formed after specimen cracking since the reinforced specimens were in uniform corrosion when they were accelerated to be corroded, so did the cracks.

\section{Results}

3.1. Mechanical Properties of Concrete. According to the Ordinary Concrete Mechanical Performance Test Method [41], the specimens for compression strength are $100 \mathrm{~mm} \times 100 \mathrm{~mm} \times 100 \mathrm{~mm}$ cubes, the specimens for modulus of elasticity are $100 \mathrm{~mm} \times 100 \mathrm{~mm} \times 300 \mathrm{~mm}$ prisms, and the specimens for splitting tensile strength are $150 \mathrm{~mm} \times 150 \mathrm{~mm} \times 150 \mathrm{~mm}$ cubes, respectively. The experimental procedures of the mechanical properties of concrete are shown in Figures 7-11.

The experimental results of the mechanical properties of concrete at 28 days are shown in Table 3.

\subsection{Relationship between Cracking Width on a Concrete Surface and Steel Corrosion Degree}

3.2.1. Effect of $W / C$. In the condition of three kinds of water-cement ratio $(0.3,0.4$, and 0.5$)$, the diameter of steel bars is $12 \mathrm{~mm}, 20 \mathrm{~mm}$, and $25 \mathrm{~mm}$, respectively, and the relationship between crack width on concrete surface and steel corrosion degree is shown in Figure 12.

Regarding the average test value as the object of discussion, in Figures 12(a)-12(c), it indicates that when the diameter of steel bars is $12 \mathrm{~mm}, 20 \mathrm{~mm}$, and $25 \mathrm{~mm}$, 


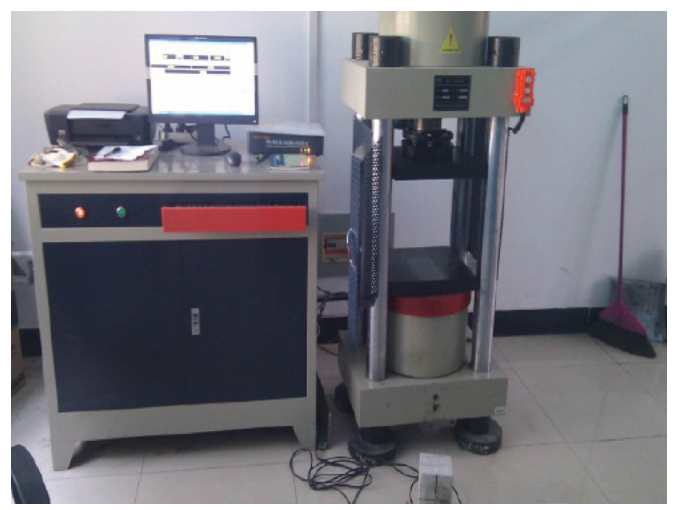

Figure 7: Compression machine and data acquisition.

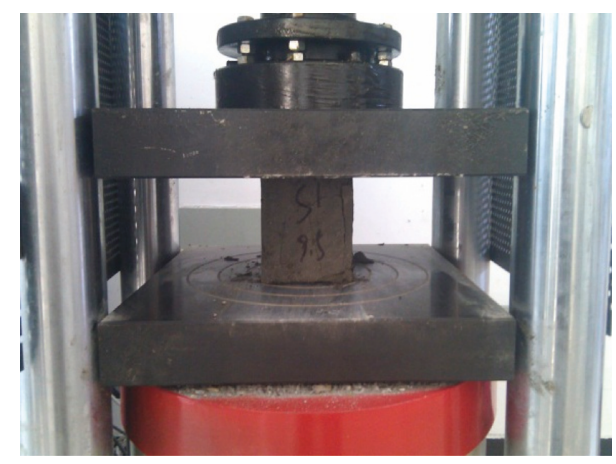

Figure 8: Test of concrete cube compressive strength.

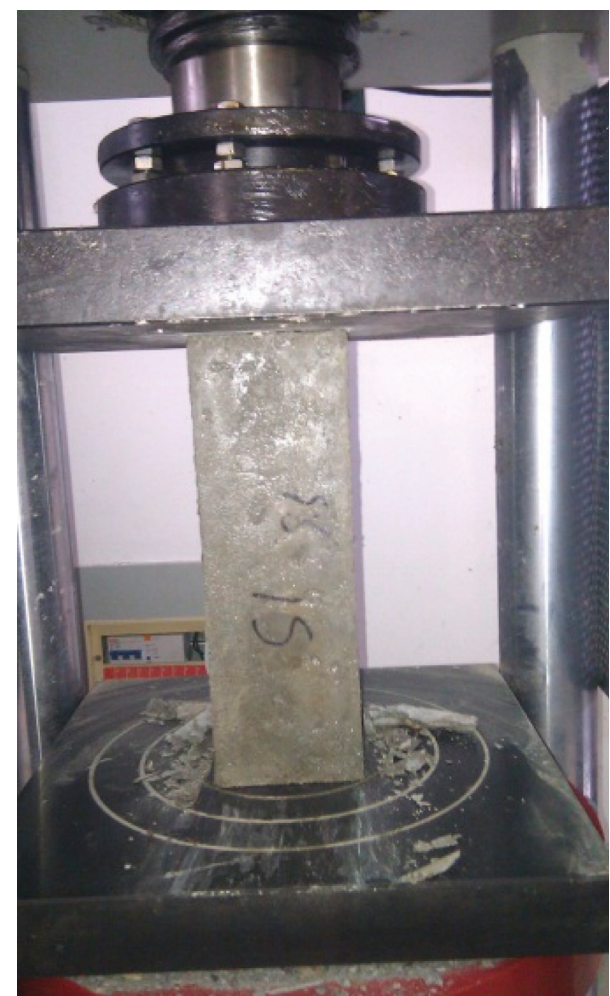

FIGURE 9: Strength of concrete prism.

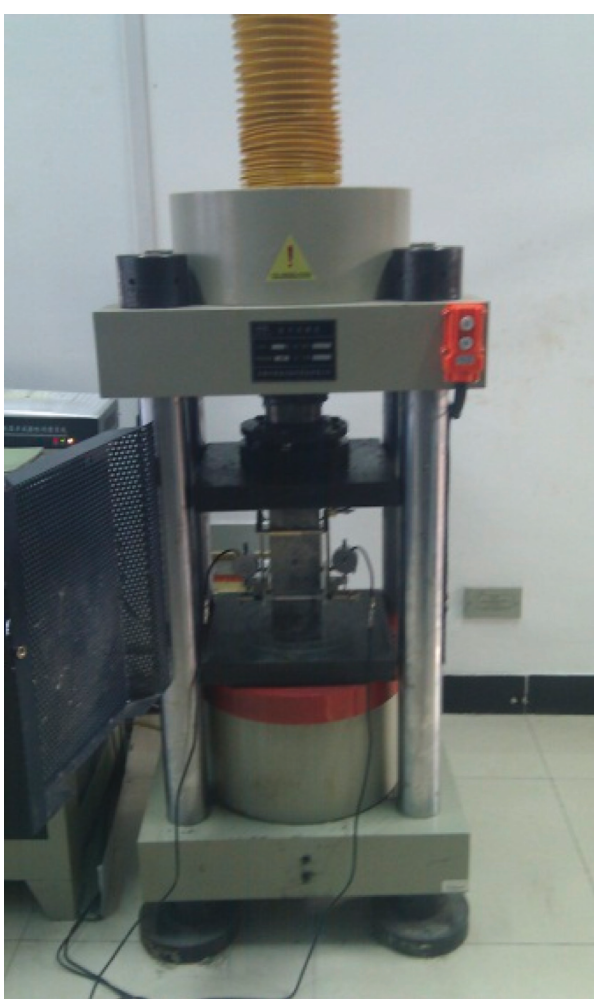

FIgURe 10: Elastic modulus of concrete.

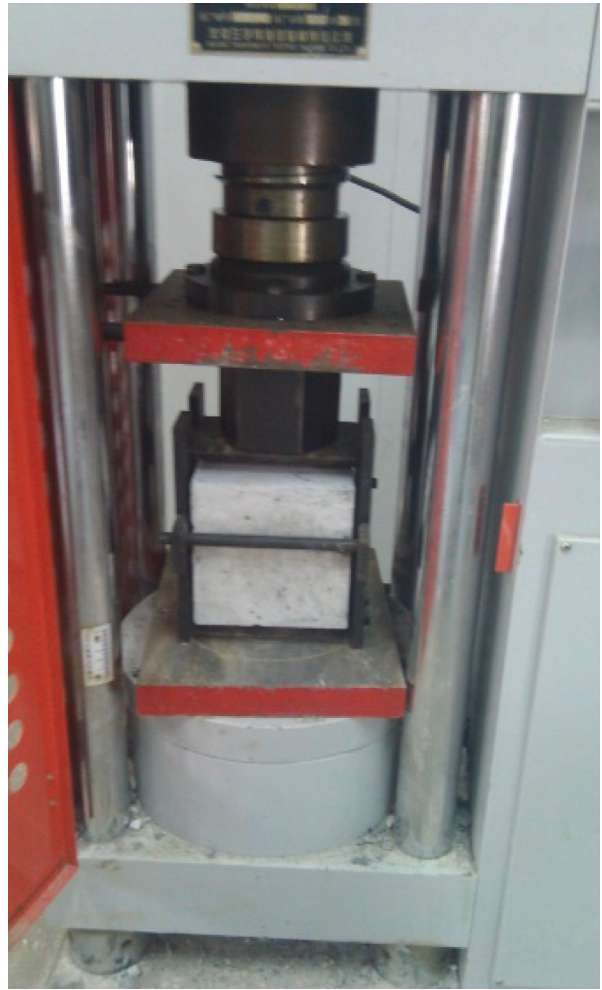

FIGURE 11: Splitting tensile strength of concrete.

respectively, reinforcement corrosion degree raises with the increase in the crack width on the concrete surface with the same water-cement ratio. When the diameter of 
TABLE 3: Experimental results of mechanical properties of concrete at 28 days.

\begin{tabular}{|c|c|c|c|c|}
\hline \multirow{2}{*}{ No. } & \multirow{2}{*}{$\mathrm{W} / \mathrm{C}$} & \multicolumn{3}{|c|}{ Experimental results } \\
\hline & & Cube compressive strength $(\mathrm{MPa})$ & Elastic modulus (GPa) & Splitting tensile strength (MPa) \\
\hline S1 & 0.3 & 58.22 & 51.13 & 3.86 \\
\hline S2 & 0.4 & 47.34 & 44.23 & 3.27 \\
\hline S3 & 0.5 & 34.90 & 37.27 & 2.88 \\
\hline
\end{tabular}

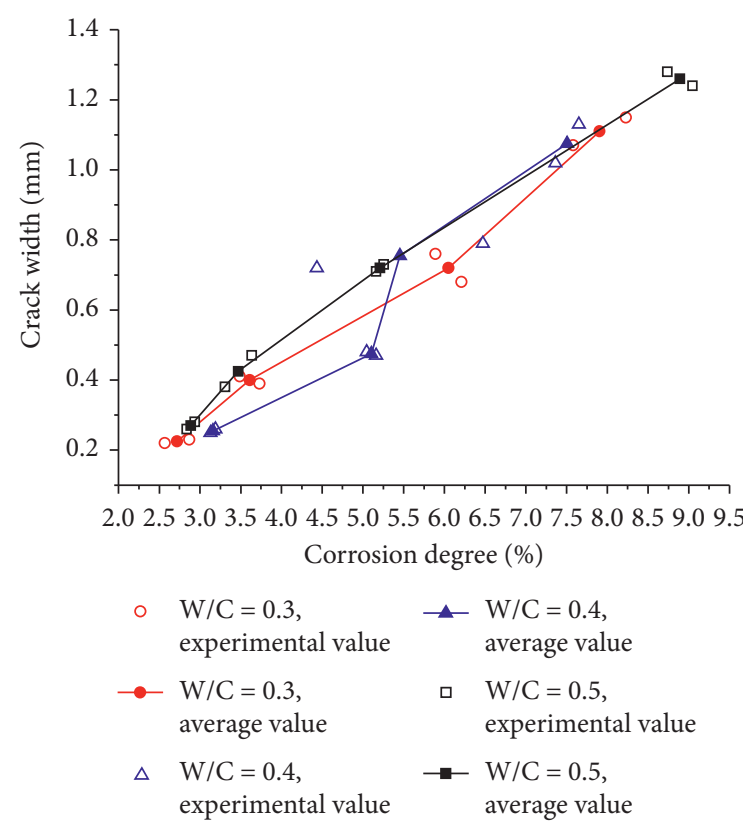

(a)

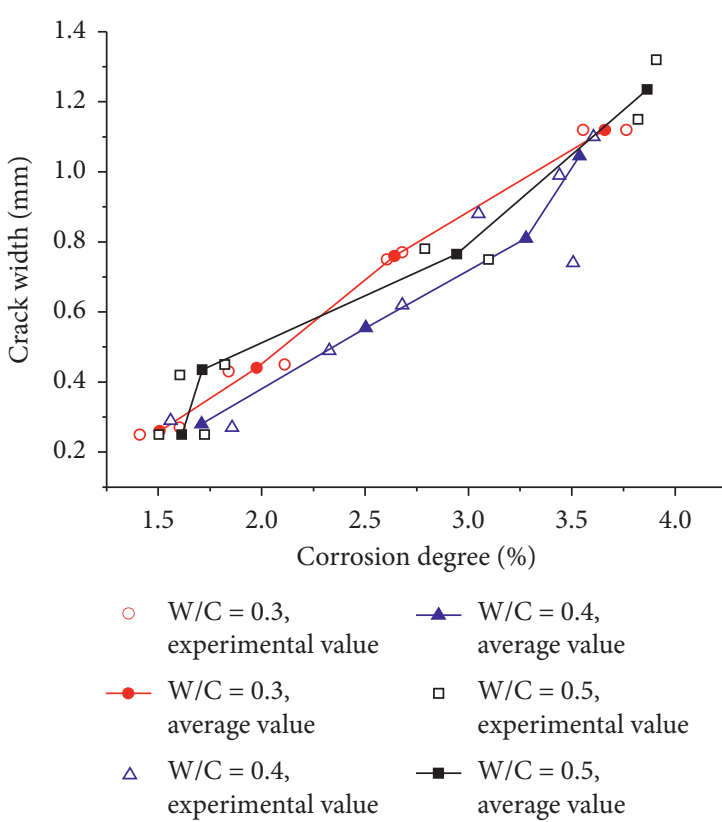

(b)

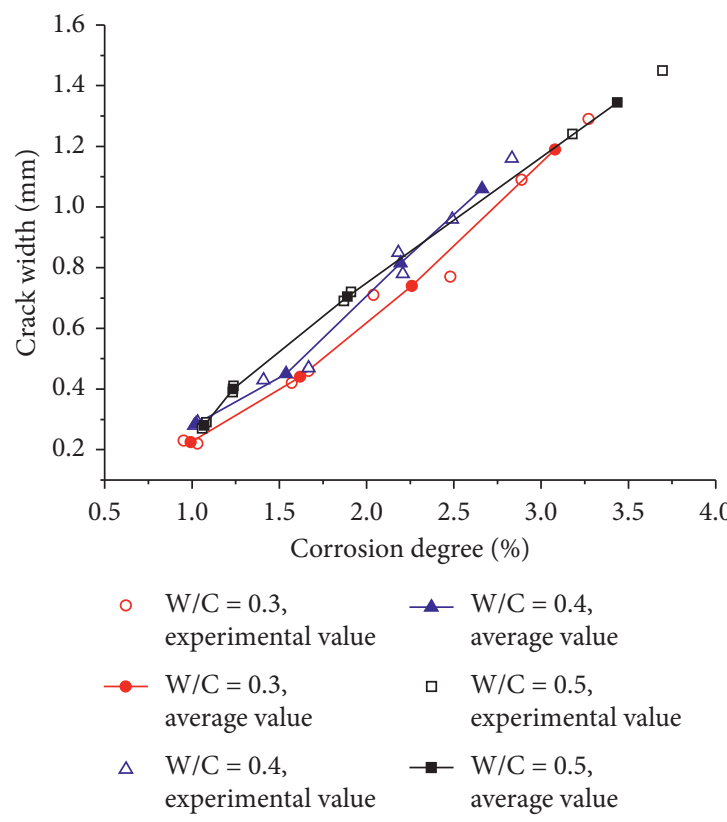

(c)

FIGURE 12: Effect of W/C on the relationship between cracking width and steel corrosion degree for different reinforcement diameters: (a) $D=12 \mathrm{~mm}$; (b) $D=20 \mathrm{~mm}$; (c) $D=25 \mathrm{~mm}$.

steel bar is $12 \mathrm{~mm}$ and the crack width on concrete surface is approximately less than $0.6 \mathrm{~mm}$, the rebar corrosion degree increases firstly and then decreases as the water-cement ratio rises. When the crack width on the concrete surface is approximately more than $0.6 \mathrm{~mm}$, the rebar corrosion degree decreases firstly and then 
increases as the water-cement ratio rises. When the diameter of the steel bar is $20 \mathrm{~mm}$, the rebar corrosion degree increases firstly and then decreases with the rising water-cement ratio. When the diameter of the steel bar is $25 \mathrm{~mm}$ and the crack width on the concrete surface is approximately less than $0.8 \mathrm{~mm}$, the steel corrosion degree decreases with the rising water-cement ratio. When the crack width on the concrete surface is approximately more than $0.8 \mathrm{~mm}$, the steel corrosion degree decreases firstly and then increases with the rising water-cement ratio.

Take the steel diameter of $12 \mathrm{~mm}$ as an example. In Figure 12(a), when the water-cement ratio is $0.3,0.4$, and 0.5 , respectively, the corrosion degree is $2.718 \%, 3.161 \%$, and $2.886 \%$, and the width of cracks on the component surface is $0.225 \mathrm{~mm}, 0.255 \mathrm{~mm}$, and $0.27 \mathrm{~mm}$ correspondingly. When the corrosion degree is $3.610 \%$, $5.104 \%$, and $3.471 \%$, the width of cracks on the component surface is corresponding to $0.40 \mathrm{~mm}, 0.475 \mathrm{~mm}$, and $0.425 \mathrm{~mm}$, respectively. The steel corrosion degree increases firstly and then decreases as the water-cement ratio rises. When the corrosion degree is $6.05 \%, 5.454 \%$, and $5.209 \%$, respectively, the width of cracks on the component surface is $0.72 \mathrm{~mm}, 0.755 \mathrm{~mm}$, and $0.72 \mathrm{~mm}$ correspondingly. The steel corrosion degree decreases with the increase in water-cement ratio. When the corrosion degree is $7.905 \%, 7.507 \%$, and $8.892 \%$, the width of cracks on the component surface is $1.11 \mathrm{~mm}, 1.075 \mathrm{~mm}$, and $1.26 \mathrm{~mm}$ correspondingly.

3.2.2. Effect of the Diameter of Steel bar. When the diameter of the steel bar is $12 \mathrm{~mm}, 20 \mathrm{~mm}$, and $25 \mathrm{~mm}$, the thickness of concrete covers is $30 \mathrm{~mm}, 40 \mathrm{~mm}$, and $50 \mathrm{~mm}$, respectively, and the relationship between crack width on concrete surface and steel corrosion degree is shown in Figure 13.

Take the average test value as the object of discussion. In Figures 13(a)-13(c), it indicates that when the thickness of concrete covers is $30 \mathrm{~mm}, 40 \mathrm{~mm}$, and $50 \mathrm{~mm}$, respectively, reinforcement corrosion degree rises with the increase in the crack width on a concrete surface with the same diameter of steel bar. For the same thickness of the concrete cover, the corrosion degree of the steel bar rises with the increase in the diameter of the steel bar under a certain crack width.

Take the thickness of concrete cover of $12 \mathrm{~mm}$ as an example. In Figure 13(b), when the diameter of steel bars is $12 \mathrm{~mm}, 20 \mathrm{~mm}$, and $25 \mathrm{~mm}$ respectively, the corrosion degree is $3.161 \%, 1.507 \%$, and $1.071 \%$, and the width of cracks on the component surface is $0.255 \mathrm{~mm}, 0.26 \mathrm{~mm}$, and $0.28 \mathrm{~mm}$ correspondingly. When the corrosion degree is $5.104 \%, 1.976 \%$, and $1.236 \%$, the width of cracks on the component surface is corresponding to $0.475 \mathrm{~mm}$, $0.44 \mathrm{~mm}$, and $0.40 \mathrm{~mm}$. When the corrosion degree is $5.454 \%, 2.643 \%$, and $1.891 \%$, the width of cracks on the component surface is $0.755 \mathrm{~mm}, 0.76 \mathrm{~mm}$, and $0.705 \mathrm{~mm}$, respectively. When the corrosion degree is $7.507 \%$, $3.661 \%$, and $3.437 \%$, the width of cracks on the component surface is $1.075 \mathrm{~mm}, 1.12 \mathrm{~mm}$, and $1.345 \mathrm{~mm}$, respectively.

3.2.3. Effect of the Thickness of Concrete Cover. When the thickness of the concrete cover is $30 \mathrm{~mm}, 40 \mathrm{~mm}$, and $50 \mathrm{~mm}$, the water-cement ratio is $0.3,0.4$, and 0.5 , respectively, and the relationship between crack width on concrete surface and steel corrosion degree is shown in Figure 14.

Take the average test value as the object of discussion. In Figures 14(a)-14(c), it indicates that when the water-cement ratio is $0.3,0.4$, and 0.5 , respectively, reinforcement corrosion degree rises with the increase in the crack width on a concrete surface with the same thickness of the concrete cover. For the same water-cement ratio, the corrosion degree of the steel bar rises with the increase in the diameter of the steel bar under a certain crack width. When the water-cement ratio is 0.3 , the steel corrosion degree decreases firstly and then increases as the thickness of the concrete cover increases. When the water-cement ratio is 0.4 , the steel corrosion degree increases firstly and then decreases as the thickness of the concrete cover increases. When the watercement ratio is 0.5 , the steel corrosion degree decreases firstly and then increases as the thickness of the concrete cover increases, which is the same as when the water-cement ratio is 0.3 .

Take the water-cement ratio equal to 0.5 as an example. In Figure 14(c), when the thickness of concrete cover is $30 \mathrm{~mm}, 40 \mathrm{~mm}$, and $50 \mathrm{~mm}$, respectively, the corrosion degree is $1.613 \%, 1.071 \%$, and $2.886 \%$, and the width of cracks on the component surface is $0.25 \mathrm{~mm}$, $0.28 \mathrm{~mm}$, and $0.27 \mathrm{~mm}$ correspondingly. When the corrosion degree is $1.713 \%, 1.236 \%$, and $3.471 \%$, the width of cracks on the component surface is $0.435 \mathrm{~mm}, 0.40 \mathrm{~mm}$, and $0.425 \mathrm{~mm}$, respectively. When the corrosion degree is $2.944 \%, 1.891 \%$, and $5.209 \%$, the width of cracks on the component surface is corresponding to $0.765 \mathrm{~mm}$, $0.705 \mathrm{~mm}$, and $0.72 \mathrm{~mm}$. When the corrosion degree is $3.865 \%, 3.437 \%$, and $8.892 \%$, the width of cracks on the component surface is $1.235 \mathrm{~mm}, 1.345 \mathrm{~mm}$, and $1.26 \mathrm{~mm}$ correspondingly.

\section{Discussion}

4.1. Validation of the Engineering Formula. The result of the test, considering the water-cement ratio is $0.3,0.4$, and 0.5 , respectively, and in which the diameter of the steel bar was $25 \mathrm{~mm}$, was analyzed. Calculation value of Li's model and the engineering formula were compared with the test results, as shown in Figure 15.

As shown in Figure 15, for different water-cement ratios, when the crack width ranges from $0.2 \mathrm{~mm}$ to $0.4 \mathrm{~mm}$, the average value of the deviation between the calculated engineering formula and experimental values is $4.27 \%$, whereas that between the calculated Li's model and experimental values is $8.65 \%$. When the crack width ranges from $0.4 \mathrm{~mm}$ to $0.7 \mathrm{~mm}$, the average value of the deviation between the calculated engineering formula and 


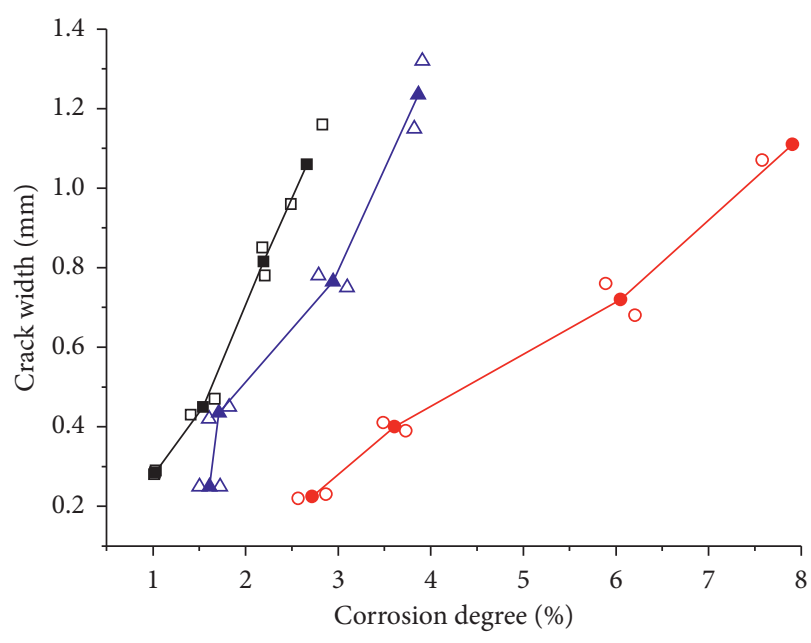

- Diameter of steel bar $=12 \mathrm{~mm}$, experimental value

- Diameter of steel bar $=12 \mathrm{~mm}$, average value

$\triangle \quad$ Diameter of steel bar $=20 \mathrm{~mm}$, experimental value

$\_$Diameter of steel bar $=20 \mathrm{~mm}$, average value

ㅁ Diameter of steel bar $=25 \mathrm{~mm}$, experimental value

$\rightarrow$ Diameter of steel bar $=25 \mathrm{~mm}$, average value

(a)

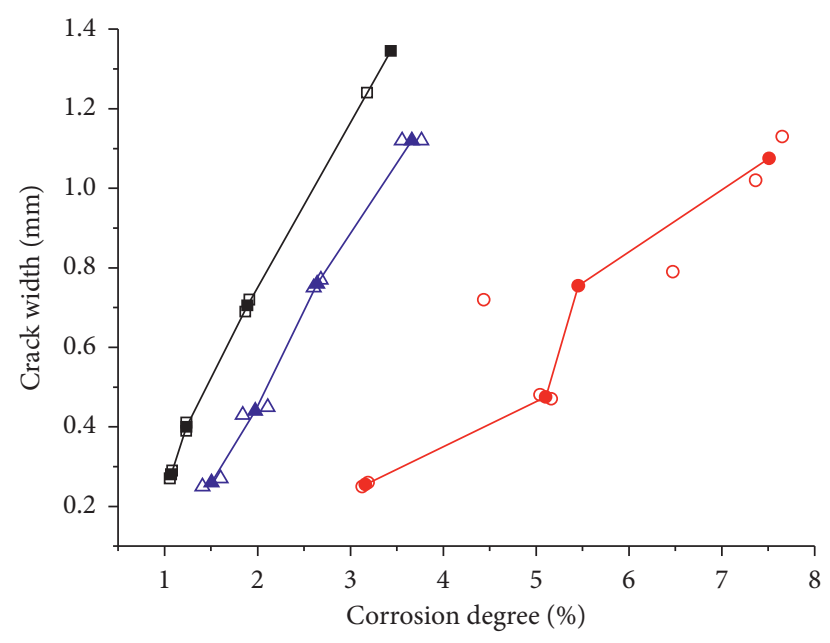

- Diameter of steel bar $=12 \mathrm{~mm}$, experimental value

- Diameter of steel bar $=12 \mathrm{~mm}$, average value

$\triangle \quad$ Diameter of steel bar $=20 \mathrm{~mm}$, experimental value

$\neg$ Diameter of steel bar $=20 \mathrm{~mm}$, average value

․ Diameter of steel bar $=25 \mathrm{~mm}$, experimental value

$\rightarrow$ Diameter of steel bar $=25 \mathrm{~mm}$, average value

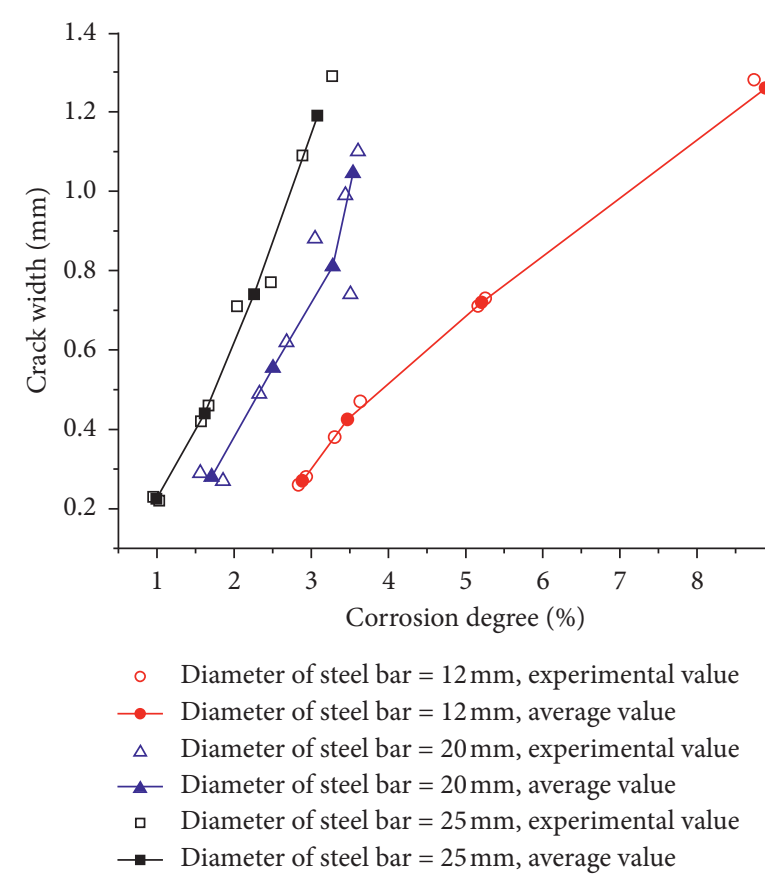

(b)

(c)

FIGURE 13: Effect of the diameter of steel bar on the relationship between cracking width and steel corrosion degree for different thickness of concrete covers: (a) $C=30 \mathrm{~mm}$; (b) $C=40 \mathrm{~mm}$; (c) $C=50 \mathrm{~mm}$.

experimental values is $6.49 \%$, whereas that between the calculated Li's model and experimental values is $9.65 \%$. When the crack widths range between $0.7 \mathrm{~mm}$ and $1.0 \mathrm{~mm}$, the average value of the deviation between the calculated engineering formula and experimental values is $3.83 \%$, whereas that between the calculated Li's model and experimental values is $7.20 \%$. When the crack width ranges from $1.0 \mathrm{~mm}$ to $1.4 \mathrm{~mm}$, the average value of the deviation between the calculated engineering formula and experimental values is $6.37 \%$, whereas that between the calculated Li's model and experimental values is $10.64 \%$. The above analyses show that, with the increase in the cracking width on the component surface, the calculation values by the engineering formula presented in this paper, comparing with that by Li's model, are in good agreement with experimental value and can be applied to predict the 


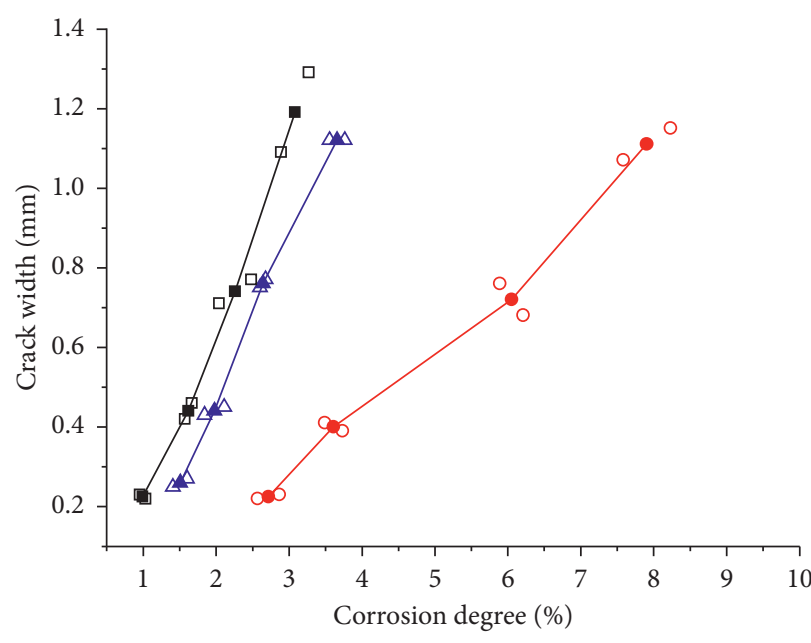

○ Concrete cover thickness $=30 \mathrm{~mm}$, experimental value

- Concrete cover thickness $=30 \mathrm{~mm}$, average value

$\triangle$ Concrete cover thickness $=40 \mathrm{~mm}$, experimental value

- - Concrete cover thickness $=40 \mathrm{~mm}$, average value

ㅁ Concrete cover thickness $=50 \mathrm{~mm}$, experimental value

$\rightarrow$ - Concrete cover thickness $=50 \mathrm{~mm}$, average value

(a)

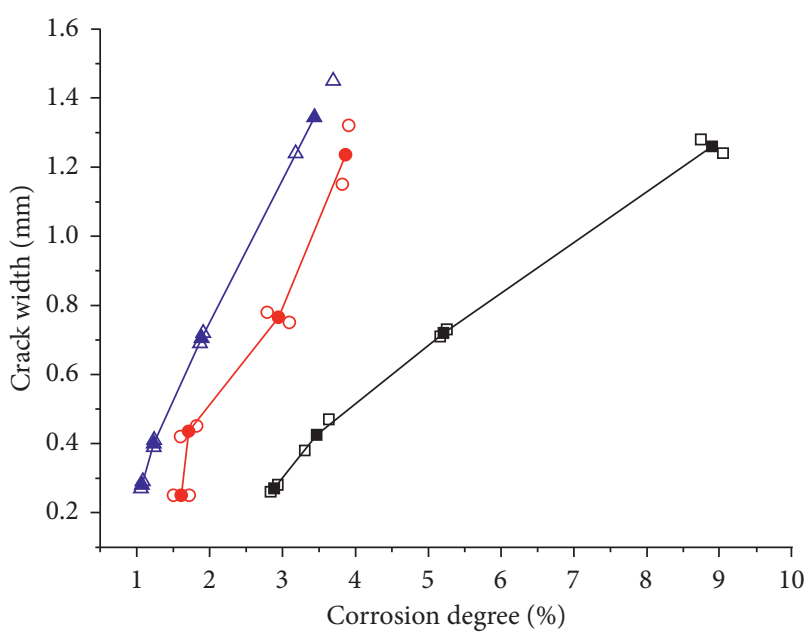

- Concrete cover thickness $=30 \mathrm{~mm}$, experimental value

$\rightarrow$ Concrete cover thickness $=30 \mathrm{~mm}$, average value

$\Delta$ Concrete cover thickness $=40 \mathrm{~mm}$, experimental value

_- Concrete cover thickness $=40 \mathrm{~mm}$, average value

․ Concrete cover thickness $=50 \mathrm{~mm}$, experimental value

$\rightarrow$ - Concrete cover thickness $=50 \mathrm{~mm}$, average value

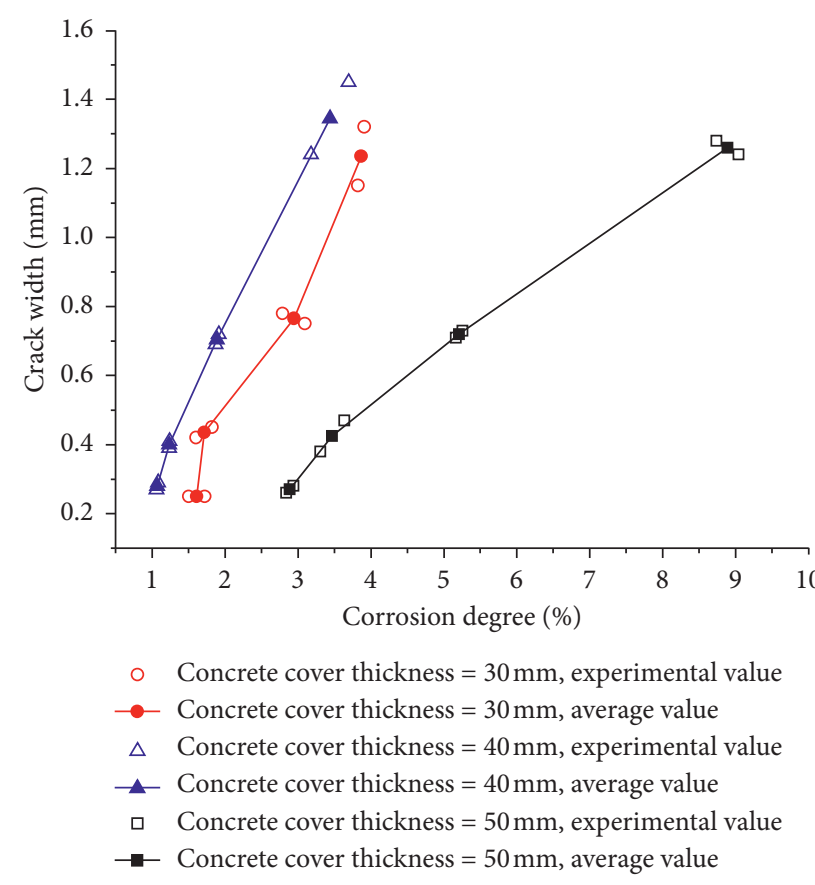

(b)

(c)

FIGURE 14: Effect of thickness of concrete cover on the relationship between cracking width and steel corrosion degree for different watercement ratios: (a) $\mathrm{W} / \mathrm{C}=0.3$; (b) $\mathrm{W} / \mathrm{C}=0.4$; (c) $\mathrm{W} / \mathrm{C}=0.5$.

corrosion degree of steel bar after concrete cracking on the component surface.

4.2. Applicability Analysis of Engineering Formula. In the practical engineering structure, the reinforced concrete structures are often subjected to load. The internal pore structure and the expansion of microcracks are closely related to the current stress state of the component. The time-dependent characteristics of concrete materials and the diffusion degree of corrosive ions in concrete will affect the corrosion of steel bars. In addition, the existence of stirrups or distributed reinforcement near the main reinforcement in the component will not only change the process of electrochemical corrosion [42] but also influence and restrict the expansion process of crack induced by corrosion. 


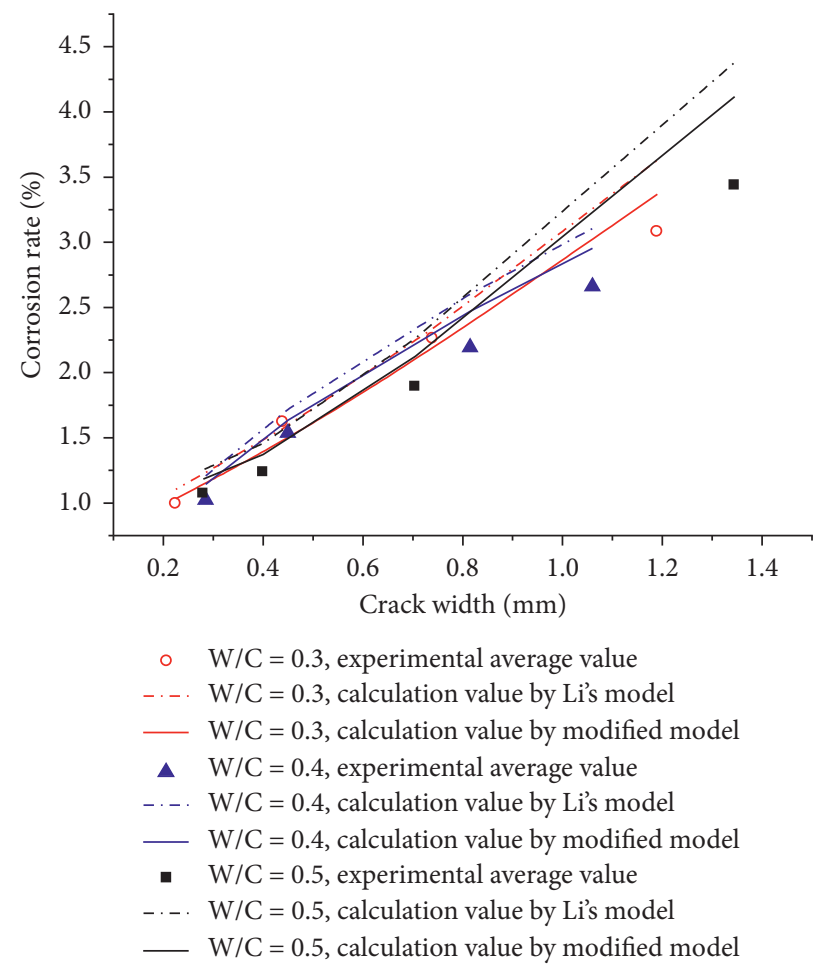

FIGURE 15: Comparison between Li's model and the engineering formula with the test results (water-cement ratio is 0.3 , 0.4 , and 0.5 ; diameter of steel bar is $25 \mathrm{~mm}$ ).

Consequently, it is necessary to carry out further research on the effect of load and the actual distribution of reinforcement in the structure on the process of cracking.

\section{Conclusions}

Undoubtedly, it is of practical significance to carry out fast and nondestructive determination of corrosion degree of steel bars for reinforced concrete structures in service for reasonable and accurate assessment on structural durability, determination of the maintenance and reinforcement measures, and redesign of the structure based on the reasonable and accurate assessment for structure durability. In this paper, the theoretical and experimental investigation of the relationship between crack width and steel corrosion degree of reinforced concrete members was carried out, and the conclusions can be obtained as follows:

(1) Li-CQ's model is established on the basis of elasticity theory. Although it can be used to describe the mechanism of corrosion expansion process in concrete caused by tensile force leading to cracking of concrete cover, its calculation process is more complex and difficult to apply, which presents obvious deviation from test results.

(2) The experiment shows that the higher the watercement ratio is, the earlier the crack appears, and the greater the corrosion degree of the steel bar is when the crack on the component surface appears. The greater the thickness of the concrete cover is, the greater the corrosion degree of the steel bar is when the crack appears. For the same water-cement ratio and thickness of the concrete cover, the corrosion degree of the steel bar decreases with the increase in the steel bar's diameter under a certain crack width.

(3) The engineering formula of the steel corrosion degree is presented by means of the simplified calculation of the stiffness reduction factor of the concrete. The comparison shows that the calculated values of the engineering formula are in good agreement with the experimental results.

\section{Data Availability}

The data used to support the findings of this study are available from the corresponding author upon request.

\section{Conflicts of Interest}

The authors declare that there are no conflicts of interest regarding the publication of this paper.

\section{Acknowledgments}

The authors would like to acknowledge the financial support of the Science and Technology Project founded by the Education Department of Jiangxi Province (Grant no. GJJ170985), the Natural Science Foundation of Jiangxi Province of China (Grant no. 20161BAB206120), and the National Innovation and Entrepreneurship Training Program for College Students (Grant no. 201911319018). 


\section{References}

[1] L. Amleh and S. Mirza, "Framework for durability-based design for concrete-steel bond against corrosion," Journal of Materials in Civil Engineering, vol. 20, no. 10, pp. 678-681, 2008.

[2] T. El Maaddawy and K. Soudki, "A model for prediction of time from corrosion initiation to corrosion cracking," Cement and Concrete Composites, vol. 29, no. 3, pp. 168-175, 2007.

[3] H. M. Shodja, K. Kiani, and A. Hashemian, "A model for the evolution of concrete deterioration due to reinforcement corrosion," Mathematical and Computer Modelling, vol. 52, no. 9-10, pp. 1403-1422, 2010.

[4] G. Nossoni and R. S. Harichandran, "Electrochemicalmechanistic model for concrete cover cracking due to corrosion initiated by chloride diffusion," Journal of Materials in Civil Engineering, vol. 26, no. 6, pp. 362-376, 2014.

[5] P. Schiessl and M. Raupach, "Laboratory studies and calculations on the influence of crack width on chloride-induced corrosion of steel in concrete," ACI Materials Journal, vol. 94, no. 1, pp. 56-62, 1997.

[6] T. Vidal, A. Castel, and R. François, "Analyzing crack width to predict corrosion in reinforced concrete," Cement and Concrete Research, vol. 34, no. 1, pp. 165-174, 2004.

[7] T. U. Mohammed, N. Otsuki, M. Hisada, and T. Shibata, "Effect of crack width and bar types on corrosionof steel in concrete," Journal of Materials in Civil Engineering, vol. 13, no. 3, pp. 194-201, 2001.

[8] Y. Y. Kim, J. M. Kim, J.-W. Bang, and S.-J. Kwon, "Effect of cover depth, w/c ratio, and crack width on half cell potential in cracked concrete exposed to salt sprayed condition," Construction and Building Materials, vol. 54, no. 11, pp. 636-645, 2014.

[9] Y. G. Du, A. H. C. Chan, L. A. Clark, X. T. Wang, F. Gurkalo, and S. Bartos, "Finite element analysis of cracking and delamination of concrete beam due to steel corrosion," Engineering Structures, vol. 56, no. 6, pp. 8-21, 2013.

[10] E. Chen and C. K. Y. Leung, "Finite element modeling of concrete cover cracking due to non-uniform steel corrosion," Engineering Fracture Mechanics, vol. 134, pp. 61-78, 2015.

[11] C. Cao, M. M. S. Cheung, and B. Y. B. Chan, "Modelling of interaction between corrosion-induced concrete cover crack and steel corrosion rate," Corrosion Science, vol. 69, pp. 97109, 2013.

[12] K. G. Papakonstantinou and M. Shinozuka, "Probabilistic model for steel corrosion in reinforced concrete structures of large dimensions considering crack effects," Engineering Structures, vol. 57, no. 4, pp. 306-326, 2013.

[13] A. Bossio, T. Monetta, F. Bellucci, G. P. Lignola, and A. Prota, "Modeling of concrete cracking due to corrosion process of reinforcement bars," Cement and Concrete Research, vol. 71, pp. 78-92, 2015.

[14] A. Bossio, G. P. Lignola, F. Fabbrocino et al., "Nondestructive assessment of corrosion of reinforcing bars through surface concrete cracks," Structural Concrete, vol. 18, no. 1, pp. 104-117, 2017.

[15] S. C. Paul, A. J. Babafemi, K. Conradie, and P. A. G. van Zijl, "Applied voltage on corrosion mass loss and cracking behaviour of steel reinforced SHCC and mortar specimens," Journal of Materials in Civil Engineering, vol. 29, no. 5, Article ID 04016272, 2017.

[16] S. C. Paul and G. P. A. G. van Zijl, "Chloride-induced corrosion modelling of cracked reinforced SHCC," Archives of
Civil and Mechanical Engineering, vol. 16, no. 4, pp. 734-742, 2016.

[17] S. C. Paul and G. P. A. G. van Zijl, "Corrosion deterioration of steel in cracked SHCC," International Journal of Concrete Structures and Materials, vol. 11, no. 3, pp. 557-572, 2017.

[18] R. K. Biswas, M. Iwanami, N. Chijiwa, and K. Uno, "Effect of non-uniform rebar corrosion on structural performance of RC structures: a numerical and experimental investigation," Construction and Building Materials, vol. 230, pp. 1-15, 2019.

[19] C. Q. Li, R. E. Melchers, and J. J. Zheng, "Analytical model for corrosion-induced crack width in reinforced concrete structures," ACI Structural Journal, vol. 103, no. 4, pp. $479-487,2006$.

[20] C. Q. Li, J. J. Zheng, W. Lawanwisut, and R. E. Melchers, "Concrete delamination caused by steel reinforcement corrosion," Journal of Materials in Civil Engineering, vol. 19, no. 7, pp. 591-600, 2007.

[21] C. Q. Li, Y. Yang, and R. E. Melchers, "Prediction of reinforcement corrosion in concrete and its effects on concrete cracking and strength reduction," ACI Materials Journal, vol. 105, no. 1, pp. 3-10, 2008.

[22] F. Li, Y. Yuan, and C.-Q. Li, "Corrosion propagation of prestressing steel strands in concrete subject to chloride attack," Construction and Building Materials, vol. 25, no. 10, pp. 3878-3885, 2011.

[23] I. Lau, C. Q. Li, and G. Y. Fu, "Prediction of time to corrosioninduced concrete cracking based on fracture mechanics criteria," Journal of Structural Engineering, vol. 145, no. 8, Article ID 04019069, 2019.

[24] D. Li, R. Wei, F. Xing, L. Sui, Y. Zhou, and W. Wang, "Influence of non-uniform corrosion of steel bars on the seismic behavior of reinforced concrete columns," Construction and Building Materials, vol. 167, pp. 20-32, 2018.

[25] X. Gu, H. Guo, B. Zhou, W. Zhang, and C. Jiang, "Corrosion non-uniformity of steel bars and reliability of corroded RC beams," Engineering Structures, vol. 167, pp. 188-202, 2018.

[26] M. Zhang, H. Song, S. Lim, M. Akiyama, and D. M. Frangopol, "Reliability estimation of corroded RC structures based on spatial variability using experimental evidence, probabilistic analysis and finite element method," Engineering Structures, vol. 192, pp. 30-52, 2019.

[27] X. Xi, S. Yang, and C.-Q. Li, "Accurate cover crack modelling of reinforced concrete structures subjected to non-uniform corrosion," Structure and Infrastructure Engineering, vol. 14, no. 12, pp. 1628-1640, 2018.

[28] Z. P. Bažant and J. Planas, Fracture and Size Effect in Concrete and Other Quasibrittle Materials, CRC Press, Boca Raton, FL, USA, 1997.

[29] E. J. Hansen and V. E. Saouma, "Numerical simulation of reinforced concrete deterioration part 2-steel corrosion and concrete cracking," ACI Materials Journal, vol. 96, no. 3, pp. 331-337, 1999.

[30] S. P. Timoshenko and J. N. Goodier, Theory of Elasticity, McGraw-Hill Book Co., New York, NY, USA, 1970.

[31] Y. Liu and R. E. Weyers, "Modeling the time-to-corrosion cracking in chloride contaminated reinforced concrete structures," ACI Materials Journal, vol. 95, no. 6, pp. 675-681, 1998.

[32] C. Q. Li, "Life-cycle modeling of corrosion-affected concrete structures: propagation," Journal of Structural Engineering, vol. 129, no. 6, pp. 753-761, 2003.

[33] Model Code 2010, First Complete Draft-Volume 1, CEB-FIP, Lausanne, Switzerland, 2010. 
[34] B. Sangoju, R. Gettu, B. H. Bharatkumar, and M. Neelamegam, "Chloride-induced corrosion of steel in cracked OPC and PPC concretes: experimental study," Journal of Materials in Civil Engineering, vol. 23, no. 7, pp. 1057-1066, 2011.

[35] K. Vu, M. G. Stewart, and J. Mullard, "Corrosion-induced cracking experimental data and predictive models," $A C I$ Structural Journal, vol. 102, no. 5, pp. 719-726, 2005.

[36] C. Andrade, C. Alonso, and F. J. Molina, "Cover cracking as a function of bar corrosion: part I-experimental test," Materials and Structures, vol. 26, no. 8, pp. 453-464, 1993.

[37] Y. Zhao, J. Yu, B. Hu, and W. Jin, "Crack shape and rust distribution in corrosion-induced cracking concrete," Corrosion Science, vol. 55, pp. 385-393, 2012.

[38] I. Khan, R. François, and A. Castel, "Prediction of reinforcement corrosion using corrosion induced cracks width in corroded reinforced concrete beams," Cement and Concrete Research, vol. 56, pp. 84-96, 2014.

[39] M. Otieno, H. Beushausen, and M. Alexander, "Chlorideinduced corrosion of steel in cracked concrete-part I: experimental studies under accelerated and natural marine environments," Cement and Concrete Research, vol. 79, pp. 373-385, 2016.

[40] D. C. Montgomery, Design and Analysis of Experiments, John Wiley \& Sons, Hoboken, NJ, USA, 8th edition, 2012.

[41] GB/T 50081-2002, Standard for Test Method of Mechanical Properties on Ordinary Concrete, China Architecture and Building Press, Beijing, China, 2002.

[42] D. Coronelli and P. Gambarova, "Structural assessment of corroded reinforced concrete beams: modeling guidelines," Journal of Structural Engineering, vol. 130, no. 8, pp. 12141224, 2004. 


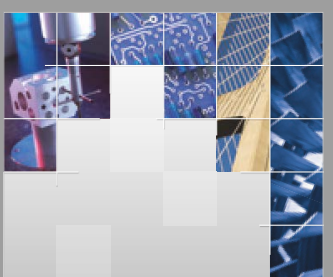

\section{Enfincering}
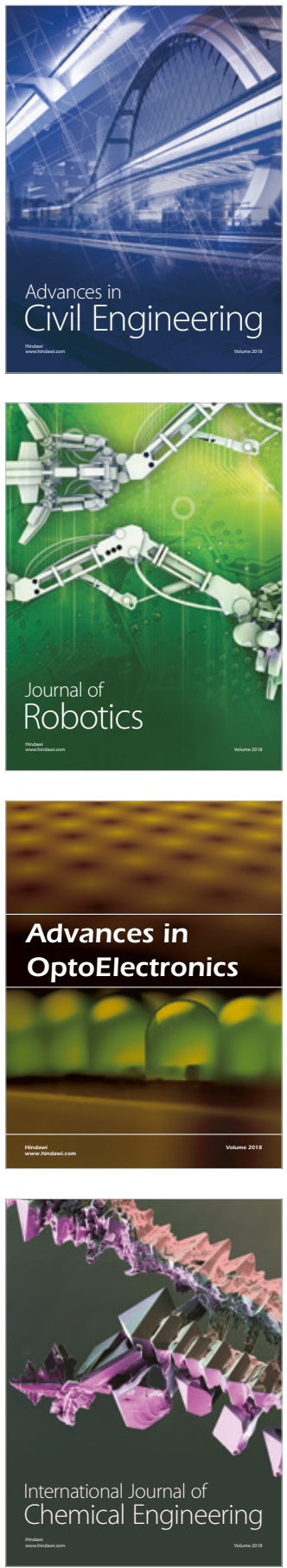

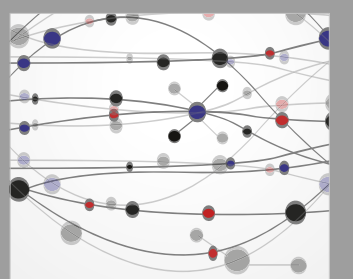

\section{Rotating \\ Machinery}

The Scientific World Journal

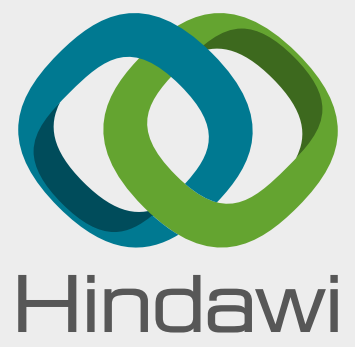

Submit your manuscripts at

www.hindawi.com
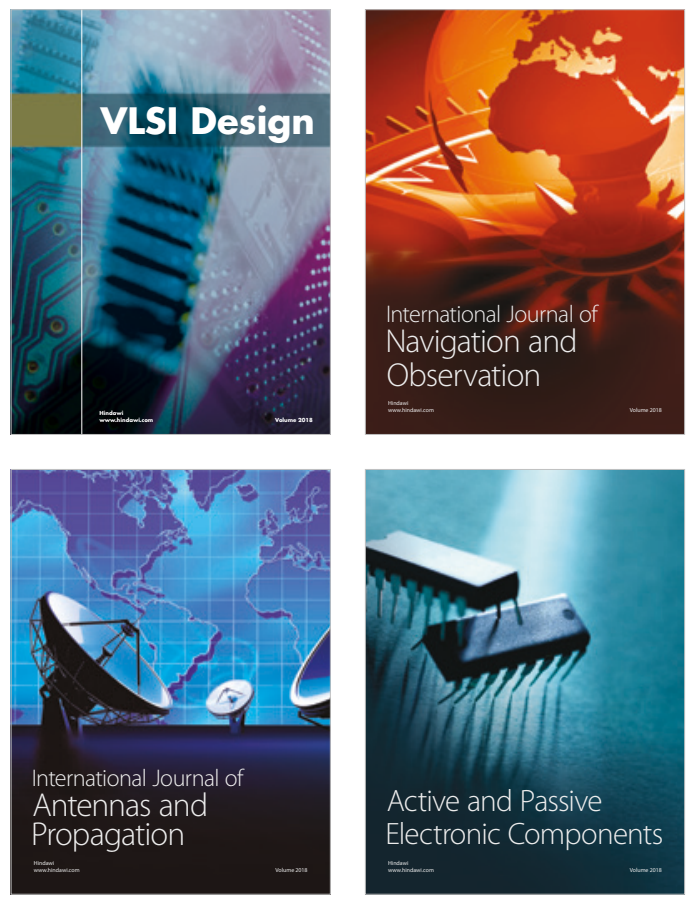
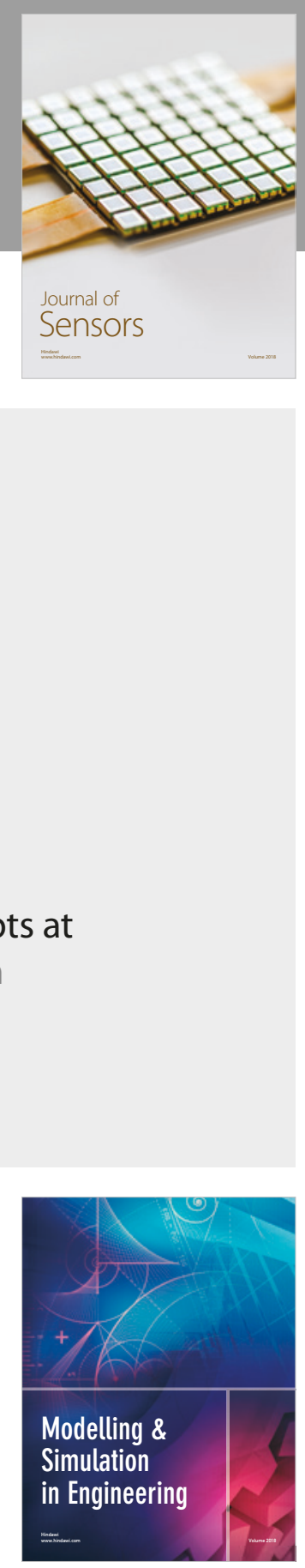

\section{Advances \\ Multimedia}
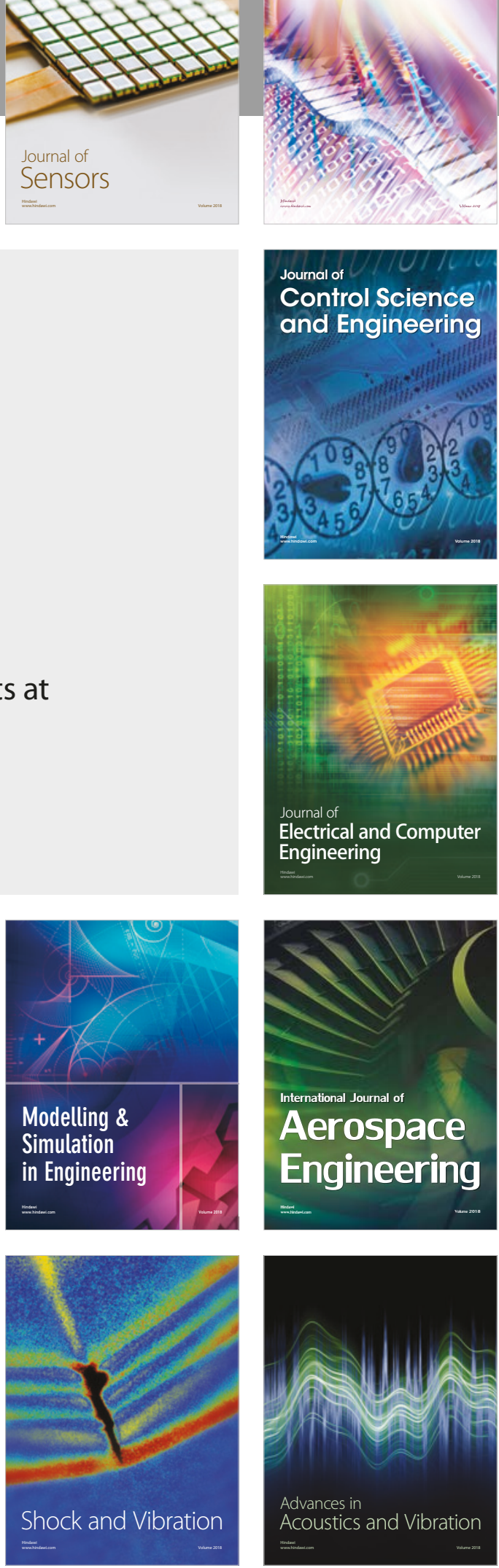